\title{
Technology, power and the political economy of new media
}

\section{Anne Mette Thorhauge and Rasmus Helles}

\author{
MedieKultur 2013, 55, 1-2
}

\section{Published by SMID | Society of Media researchers In Denmark | www.smid.dk The online version of this text can be found open access at www.mediekultur.dk}

Recent developments in digital communication technologies have challenged commonly held notions of media systems and the power and production relations that they involve. The networked, global nature of new media has challenged previously well-known orders of business. For example, the introduction of new platforms (smartphones, tablets) not only makes content available to consumers in new ways, but also undermines existing constellations of power and influence between actors at different points in the chain from content production to consumption. Many analyses of the changes to modes of production in the media sector have portrayed these as challenges to established business models. Yet despite the obvious - and sometimes life-threatening - challenges to the ways in which media businesses make a living, the development of digital media changes more than just the financial games of the market. The spread of digital media points back to some of the fundamental issues of the political economy regarding the interlocking relations between media technologies, power and discourse. In this sense, digital media prompts us to revisit some of the founding debates of modern media studies, and engage once again in critical analyses of the intricate ways in which positions of power are contested, established and used through the orchestration of media technologies across different domains.

The aim of this special issue is to offer series of detailed analyses of the political economy of digital media. The issue includes critical inquiries into the ways in which old media systems and power structures "translate" into new media schemes and the ways new types of media systems and power structures emerge with the spread and adoption of new 
media technologies. As regards the translation of existing power relations into new media schemes, Neumeyer and Valtysson's article "Tweet against the Nazis" identifies the "tactics, media practices, and strategies" used by activists on Twitter and discusses the concept of power as an interplay between the technical affordances of Twitter and the more general political and socio-cultural context. With the article "PSB goes personal", Sørensen discusses how old media systems such as public service media struggle to realize the potential for the personalization of their Web interfaces for individual users, while at the same time balancing the requirements of established formats of journalism and the pressure from commercial media. In "Politics, pleasure, violence", Stoehrel gives a critical analysis of the way the Swedish military has appropriated new media technologies as a powerful tool for communicating its particular worldview and gaining support for its economic interests. Finally, Bechmann's contribution, "Internet profiling", maps the data strategies of some of the largest Web companies in the world, Facebook and Google, and shows how core differences in the handling and commercialization of user data are reflected in the ethical and social consequences of their strategies.

These articles represent highly diverse perspectives on the concept of political economy, yet share a common focus on the (re)production and contestation of power as a crucial aspect of the appropriation and management of new media technologies. Taken together, they show how the political economy of new media involves, on the one hand, a partial reproduction and adaption of old power relations and media systems into new media schemes and, on the other hand, an introduction of a new set of actors and principles, such as specific technological affordances, data strategies and algorithmic gatekeeping that challenge old power relations and media systems.

Anne Mette Thorhauge

Associate Professor, PhD

Department of Media, Cognition and Communication University of Copenhagen, Denmark annemette@thorhauge.dk

Rasmus Helles

Associate Professor, PhD

Department of Media, Cognition and Communication University of Copenhagen, Denmark rashel@hum.ku.dk 